Research Article

\title{
Dynamic Air Target Threat Assessment Based on Interval-Valued Intuitionistic Fuzzy Sets, Game Theory, and Evidential Reasoning Methodology
}

\author{
Ruojing Zhao $(\mathbb{D}$, Fengbao Yang $(\mathbb{D}$, Linna Ji, and Yongqiang Bai \\ North University of China, Taiyuan, Shanxi 030051, China \\ Correspondence should be addressed to Fengbao Yang; yfengb@163.com
}

Received 15 October 2020; Revised 8 May 2021; Accepted 21 May 2021; Published 9 June 2021

Academic Editor: Emilio Insfran Pelozo

Copyright (c) 2021 Ruojing Zhao et al. This is an open access article distributed under the Creative Commons Attribution License, which permits unrestricted use, distribution, and reproduction in any medium, provided the original work is properly cited.

\begin{abstract}
In order to reduce the uncertainty of target threat assessment results and improve exact target assessment in the complicated and changeable air combat environment, a novel method based on the combination of interval-valued intuitionistic fuzzy sets (IVIFSs), game theory, and evidential reasoning methodology is proposed in this paper. First, the imprecise and fuzzy information of battlefield air target is expressed by IVIFS. Second, the optimal index weight is determined by the interval intuitionistic fuzzy entropy and game theory. And the time series weight is calculated by the inverse Poisson distribution method. Then, the target evaluation information at different times is dynamically fused through an evidential reasoning algorithm. Finally, the accuracy function is applied to obtain the threat ranking of all the targets. A case of the threat assessment of air targets is provided to demonstrate the implementation process of the method proposed in this paper. Simulation experiments show that in a rapidly evolving combat environment, this algorithm can effectively reduce the uncertainty of target threat assessment results. It provides us with a useful way for target threat assessment based on interval-valued intuitionistic fuzzy sets, game theory, and evidential reasoning methodology.
\end{abstract}

\section{Introduction}

With the development of weaponry information technology, the battlefield environment becomes more complicated and diversified. How to effectively use battlefield target information to assist commanders in making scientific decisions has always been the focus of battlefield research $[1,2]$. Since air combat plays a vital role in the trend of the modern battlefield, the efficient threat assessment of incoming targets can be used as a reference for reasonably allocating defensive firepower [3]. Hence, it is very necessary to carry out research on air threat assessment methods since it can provide an effective auxiliary decision-making method for the field of air defense operations.

Target threat assessment aims to analyze the operational capabilities of incoming enemy targets and obtain a quantitative description of the degree of the enemy target threat [4]. To solve the target threat assessment problem, air target threat assessment methods have been proposed. These methods mainly include Bayesian networks [5-7], neural networks [8,9], rough sets [10], the cloud model [11], and so on $[12,13]$. These methods are suitable for different battlefield environments and have different characteristics. However, these methods express the target information by crisp numerical numbers and do not fully consider the fuzziness and uncertainty of battlefield target information.

In recent years, the intuitionistic fuzzy set (IFS) [14] has been defined as a union of the membership and nonmembership functions and the degree of hesitation. IFSs can describe the fuzziness and uncertainty of target information and have been widely used in target threat assessment [15-18]. In [15], IFSs are used to construct an intuitionistic fuzzy target information matrix and conduct target threat assessment. Due to the complex and changeable modern battlefield environment, the threat membership of battlefield targets cannot be given an exact value, resulting in a certain 
degree of limitations in the application of IFSs in the field of target threat assessment. Atanassov and Gargov [19] further extended the IFS and proposed the interval-valued intuitionistic fuzzy set (IVIFS), using interval numbers instead of exact values to represent membership and nonmembership. IVIFS can better describe the uncertainty and fuzziness of the decision-making process, which has attracted the attention of a large number of scholars. The research of interval intuitionistic fuzzy sets mainly focuses on the entropy $[20,21]$, intuitionistic fuzzy divergence $[22,23]$, knowledge measure [24], ranking method [25], and similarity [26] of interval-valued intuitionistic fuzzy sets. These theoretical research studies promote the application of IVIFS in decision-making fields, such as alternative fuel technology options [27], hydrogen production evaluation process [28], supplier selection problem [29], car-sharing problems [30], stock investment selection [31], and hotel location [32]. Among the exiting studies, the assessment of air targets based on IVIFS was seldom reported.

How to fuse IVIFS information effectively is the key to solving the decision-making problem with IVIFS. In [33], induced intuitionistic fuzzy ordered weighted geometry is developed to solve venture capital project selection problems. In [34], interval-valued intuitionistic fuzzy ordered weighted aggregation is proposed to solve the supplier optimization problem. Although the aggregator in the above method solves the information fusion problem in related fields, the shortcoming is that the uncertainty of the evaluation result in the information fusion process is increased by ignoring hesitation information. Fortunately, the evidential reasoning methodology (ERM) is an effective means of fusing information [35-43]. In [37], the evidential reasoning algorithm is adopted to aggregate the weighted evidentiary sources and is suitable for dealing with conflicts in information fusion. In [38], ERM is adopted to aggregate the decision matrix, which improves the rationality of the decision process. In [42], the ERM is used to fuse intuitionistic fuzzy sets, instead of the aggregator. The ERM has a strong ability to aggregate intuitionistic fuzzy sets. As seen from the above study, the ERM has a good data fusion capability which can avoid information loss and retain hesitation intuitionistic fuzzy information.

Meanwhile, existing target threat assessment methods $[2,4]$ and [10-12] only use the target measurement information at the current time for the evaluation, which means that it is difficult to comprehensively analyze the target threat level for a period of times after discarding the observation data before the current time. Without fully considering the dynamic changes of the target attributes, the results of these methods are one-sided and unreasonable to a certain extent.

To sum up, IVIFS is suitable for dealing with ambiguity and inaccurate battlefield target information, but it only uses the current target measurement information to evaluate. In order to meet the needs of the dynamic battlefield, a novel target threat assessment method based on IVIFS, game theory, and the ERM is proposed. The proposed method can effectively reduce the uncertainty of the target threat assessment and adapt to the requirements of a dynamic battlefield. Moreover, the optimal index weights are calculated through the combination interval intuitionistic fuzzy entropy and game theory method, which is used to eliminate the data sensitivity of the index weight and makes the assessment result more reliable.

The rest of this paper is organized as follows. Section 2 presents the basic theory of the IVIFS and ERM. Section 3 introduces the calculation method of the optimal attribute weight and the time series weight. A novel air threat assessment method based on the IVIFS, game theory, and the ERM is presented in Section 4. Section 5 presents an example analysis and comparison discussion. The conclusions are drawn in Section 6.

\section{Preliminaries}

\subsection{Interval-Valued Intuitionistic Fuzzy Sets}

Definition 1. In [19], the interval-valued intuitionistic fuzzy set (IVIFS) is proposed by Atanassov and Gargov. The domain $X$ is a finite nonempty set and IVIFS $A$ can be described as follows:

$$
A=\left\{\left(x, \mu_{A}(x), v_{A}(x)\right): x \in X\right\},
$$

where the intervals $\mu_{A}(x)$ and $\nu_{A}(x)$, respectively, denote the degrees of membership and nonmembership of element $x$ of IVIFS A. $\mu_{A}(x)=\left[\mu_{A L}(x), \mu_{A U}(x)\right]$ and $v_{A}(x)=\left[v_{A L}(x), v_{A U}(x)\right]$, where $0 \leq \mu_{A U}(x)+v_{A U}(x) \leq 1$, $\mu_{A L}(x) \geq 0, v_{A L}(x) \geq 0$, and $\forall x \in X$. In addition, $\pi_{A}(x)=$ $1-\mu_{A}(x)-\nu_{A}(x)$ indicates the degree of uncertainty (degree of hesitation) for element $x$ that belongs to $A$, where $\pi_{A L}(x)=1-\mu_{A U}(x)-v_{A U}(x) \quad$ and $\quad \pi_{A U}(x)=1$ $-\mu_{A L}(x)-v_{A L}(x)$. When $\mu_{A L}(x)=\mu_{A U}(x)$ and $v_{A L}(x)=v_{A U}(x)$, the IVIFS degenerates into an intuitionistic fuzzy set (IFS).

Definition 2. In [43], Ye presents the accuracy function to transform an interval-valued intuitionistic fuzzy value $\widetilde{A}=$ $\left\langle\left(\mu_{A L}(x), \mu_{A U}(x)\right),\left(v_{A L}(x), v_{A U}(x)\right)\right\rangle$ into a real value $M(A)$, and it is given as follows:

$$
M(A)=\mu_{A L}(x)+\mu_{A U}(x)-1+\frac{v_{A L}(x)+v_{A U}(x)}{2} .
$$

2.2. Evidential Reasoning Methodology (ERM). In the following, a brief review is given of the ERM method for multiattribute decision analysis under uncertain environments [38]. Let $X=\left\{x_{1}, x_{2}, \ldots x_{m}\right\}$ be a set of alternatives, $A=\left\{a_{1}, a_{2}, \ldots a_{n}\right\} \quad$ be $a$ set of attributes, and $W=\left\{w_{1}, w_{2}, \ldots w_{n}\right\}$ be a set of weights. where $0 \leq w_{j} \leq$ $1,0 \leq j \leq n, \sum_{j=1}^{n} w_{j}=1$. Assume that there are $p$ evaluation grades $H_{1}, H_{2}, \ldots, H_{p}$ for assessing the attributes of alternatives. $H_{1}, H_{2}, \ldots, H_{p}$ assess the attributes of alternatives. Let $\beta_{q, j}\left(x_{i}\right)$ be a degree of belief that attribute $a_{j}$ of alternative $x_{i}$ is assessed theevaluation grade $H_{q}$, where $0 \leq \beta_{q, j}\left(x_{i}\right) \leq 1$ and $\sum_{q=1}^{p} \beta_{q, j}\left(x_{i}\right) \leq 1$. Let $N\left(a_{j}\left(x_{i}\right)\right)$ denote the evaluation value of attribute $a_{j}$ with respect to alternative $x_{i}$, and it is defined as follows: 


$$
N\left(a_{j}\left(x_{i}\right)\right)=\left\{H_{q}, \beta_{q, j}\left(x_{i}\right)\right\},
$$

where $H_{q}$ is an evaluation grade, $0 \leq i \leq m$, and $0 \leq j \leq n$. The assessments of the attributes of the alternatives are represented by a decision matrix $D$, which is shown as follows:

$$
D=N\left(a_{j}\left(x_{i}\right)\right)_{m \times n},
$$

where $0 \leq i \leq m$ and $0 \leq j \leq n$. Based on the decision matrix $D$, we can aggregate the evaluation values of the attributes of each alternative $x_{i}$, where $0 \leq i \leq m$, and the details are as follows.

First, the degree of belief $\beta_{q, j}\left(x_{i}\right)$ of the evaluation grade $H_{q}$ of an attribute $a_{j}$ for the alternative $x_{i}$ is transformed into the basic probability mass $\beta_{q, j}\left(x_{i}\right)$ where

$$
m_{q, j}\left(x_{i}\right)=w_{j} \beta_{q, j}\left(x_{i}\right) .
$$

$1 \leq q \leq p, 0 \leq i \leq m$, and $0 \leq j \leq n$. Let $m_{H, j}\left(x_{i}\right)$ be the remaining probability mass of attribute $a_{j}$ for an alternative $x_{i}$, which is shown as follows:

$$
\begin{aligned}
& m_{H, j}\left(x_{i}\right)=\bar{m}_{H, j}\left(x_{i}\right)+\widetilde{m}_{H, j}\left(x_{i}\right), \\
& \bar{m}_{H, j}\left(x_{i}\right)=1-w_{j}, \\
& \widetilde{m}_{H, j}\left(x_{i}\right)=w_{j}\left(1-\sum_{q=1}^{p} \beta_{q, j}\left(x_{i}\right)\right),
\end{aligned}
$$

where $\bar{m}_{H, j}\left(x_{i}\right)$ is the first part of the remaining probability mass, which is caused by the weight, and $\widetilde{m}_{H, j}\left(x_{i}\right)$ is the second part of the remaining probability mass that has not yet been assigned individual grades, which is due to the incompleteness in the assessment $N\left(a_{j}\left(x_{i}\right)\right)$.

Next, the basic probability mass matrix ${ }_{s}$ is obtained:

$$
s=\left(m_{1, j}\left(x_{i}\right), \ldots, m_{p, j}\left(x_{i}\right)\right)_{m \times n^{\prime}}
$$

where $\sum_{q=1}^{p} m_{q, j}\left(x_{i}\right) \leq 1,0 \leq i \leq m$, and $0 \leq j \leq n$.

Compute the combined probability mass $m_{q, I(y)}\left(x_{i}\right)$ of each attribute $a_{y}$ of alternative $x_{i}$ as follows:

$$
\begin{aligned}
m_{q, I(y)}\left(x_{i}\right)= & \lambda_{I(y)}\left(x_{i}\right)\left(m_{q, I(y-1)}\left(x_{i}\right) m_{q, y}\left(x_{i}\right)\right. \\
& \left.+m_{q, I(y-1)}\left(x_{i}\right) m_{H, y}\left(x_{i}\right)+m_{H, I(y-1)}\left(x_{i}\right) m_{q, y}\left(x_{i}\right)\right),
\end{aligned}
$$

$$
m_{H, I(y)}\left(x_{i}\right)=\lambda_{I(y)}\left(x_{i}\right) m_{H, I(y-1)}\left(x_{i}\right) m_{H, y}\left(x_{i}\right) .
$$
where

Let $m_{I(1)}\left(x_{i}\right)=m_{q, 1}\left(x_{i}\right)$ and $m_{H, I(1)}\left(x_{i}\right)=m_{H, 1}\left(x_{i}\right)$,

$$
\lambda_{I(y)}\left(x_{i}\right)=\left(1-\sum_{t=1}^{2} \sum_{\substack{g=1 \\ y \neq t}}^{2} m_{t, I(y-1)}\left(x_{i}\right) m_{g, y}\left(x_{i}\right)\right)^{-1}
$$

$$
2 \leq y \leq n, 1 \leq q \leq p, 1 \leq i \leq m .
$$

Based on (9) and (10), after aggregating the evaluation values of the attributes of alternative $x_{i}$, we get the degree of belief $\beta_{q}\left(x_{i}\right)$ of alternative $x_{i}$ regarding evaluation grade $H_{q}$, which is shown as follows:

$$
\begin{aligned}
& \beta_{q}\left(x_{i}\right)=\left(1-\beta_{H}\left(x_{i}\right)\right) \frac{m_{q, I(n)}\left(x_{i}\right)}{1-m_{H, I(n)}\left(x_{i}\right)}, \\
& \beta_{H}\left(x_{i}\right)=\sum_{j=1}^{n} w_{k}\left(1-\sum_{q=1}^{p} \beta_{q, j}\left(x_{i}\right)\right),
\end{aligned}
$$

$\beta_{H}\left(x_{i}\right)$ is the degree of belief produced by an unknown information, where $\sum_{q=1}^{p} \beta_{q}\left(x_{i}\right)+\beta_{H}\left(x_{i}\right)=1,1 \leq q \leq p$, and $0 \leq i \leq m$.

\section{Weight Determination}

3.1. Determination of Assessment Index Weight. When using IVIFSs to assess target threats, the assessment index weight $\omega$ is included in the calculation of the IVIFS data fusion process; thus, the weight value of each index affects the final evaluation result. The impact of each attribute index on the final degree of the threat is different; therefore, attribute indicators should be given different weights. In this paper, the interval-valued intuitionistic fuzzy entropy and game theory are used to determine the weights of the attributes.

\subsubsection{Determination of Assessment Index Weights.}

Step 1. Determine the IVIFS matrix $X^{(k)}$ of the assessment index at time $t_{k}$, where $X^{(k)}=\left(\widetilde{x}_{i j}^{(k)}\right)_{m \times n}$ and $\tilde{x}_{i j}^{(k)}=\left\langle\left[\mu_{i j L}^{(k)}, \mu_{i j U}^{(k)}\right],\left[\nu_{i j L}^{(k)}, v_{i j U}^{(k)}\right]\right\rangle$, and $\tilde{x}_{i j}^{(k)}$ is simplified as $\tilde{x}_{i j}^{(k)}=\left\langle\left[a_{i j}^{(k)}, b_{i j}^{(k)}\right],\left[c_{i j}^{(k)}, d_{i j}^{(k)}\right]\right\rangle$.

Step 2. Wei et al. [44] proposed an effective method based on the intuitionistic fuzzy entropy, which is defined as follows:

$$
H_{j}^{(k)}=\frac{1}{m} \sum_{i=1}^{m} \frac{2-\left|a_{i j}^{(k)}-c_{i j}^{(k)}\right|-\left|b_{i j}^{(k)}-d_{i j}^{(k)}\right|+\pi_{i j}^{L(k)}+\pi_{i j}^{U(k)}}{2+\left|a_{i j}^{(k)}-c_{i j}^{(k)}\right|+\left|b_{i j}^{(k)}-d_{i j}^{(k)}\right|+\pi_{i j}^{L(k)}+\pi_{i j}^{U(k)}} .
$$

Step 3. The weight of attribute $j$ at time $t_{k}$ is calculated as

$$
w_{j}^{(k)}=\frac{1-H_{j}^{(k)}}{n-\sum_{j=1}^{n} H_{j}^{(k)}}
$$

3.1.2. Determine the Optimal Attribute Weight Using Game Theory. The index weight determination method based on the interval-valued intuitionistic fuzzy entropy is sensitive to the data. Game theory is used to eliminate the sensitivity of the attribute weights at different times to obtain the optimal attribute weight.

Step 1. Construct possible attribute weight sets.

An attribute weight set $w^{(k)}=\left(w_{1}^{(k)}, w_{2}^{(k)}, \ldots, w_{n}^{(k)}\right)$ is obtained using the interval-valued intuitionistic fuzzy entropy at different times $t_{k}(1 \leq k \leq l)$, and then a set of basic attribute weight vectors $\left\{w_{1}, w_{2}, \ldots, w_{l}\right\}$ is constructed. Let any linear combination of $l$ attribute weight vectors be 


$$
\mathbf{w}=\sum_{k=1}^{l} \sigma_{k} w_{k}^{T}
$$

where $\sigma_{k}$ is the linkage combination coefficient and $\mathbf{w}$ is a possible attribute weight vector based on the basic attribute weights. The entire collection $\left\{\mathbf{w} \mid \mathbf{w}=\sum_{k=1}^{l} \sigma_{k} w_{k}^{T}, \sigma_{k}>0\right\}$ represents a set of possible attribute weight vectors.

Step 2. Find the optimal attribute weight vector $\mathbf{w}^{*}$.

The optimal attribute weight vector is calculated using the game strategy model. In the selection process, the linkage coefficient $\sigma_{k}$ should be optimized based on the objective of minimizing the deviation of $w$ and $w_{k}$, and the optimization model is derived as follows:

$$
\min \left\|\sum_{j=1}^{l}\left|\sigma_{i}\right| w_{j}^{T}-w_{i}^{T}\right\|_{2}, \quad(i=1,2, \ldots, l) .
$$

By solving the model, the optimal attribute weight results among the attribute weights can be obtained. According to the differential properties of the matrix, the optimal first derivative condition of equation (15) is as follows:

$$
\sum_{j=1}^{l}\left|\sigma_{j}\right| w_{i} w_{j}^{T}=w_{i} w_{i}^{T}, \quad(i=1,2, \ldots, l) .
$$

The matrix form of the linear equation system corresponding to equation (16) is as follows:

$$
\left[\begin{array}{cccc}
w_{1} \cdot w_{1}^{T} & w_{1} \cdot w_{2}^{T} & \cdots & w_{1} \cdot w_{l}^{T} \\
w_{2} \cdot w_{1}^{T} & w_{2} \cdot w_{2}^{T} & \cdots & w_{2} \cdot w_{l}^{T} \\
\ldots & \cdots & \cdots & \cdots \\
w_{L} \cdot w_{1}^{T} & w_{L} \cdot w_{2}^{T} & \cdots & w_{l} \cdot w_{l}^{T}
\end{array}\right]\left[\begin{array}{c}
\sigma_{1} \\
\sigma_{2} \\
\cdots \\
\sigma_{l}
\end{array}\right]=\left[\begin{array}{c}
w_{1} \cdot w_{1}^{T} \\
w_{2} \cdot w_{2}^{T} \\
\cdots \\
w_{l} \cdot w_{l}^{T}
\end{array}\right] .
$$

According to equation (17), $\left(\sigma_{1}, \sigma_{2}, \ldots, \sigma_{L}\right)$ is obtained, and the normalization is as follows:

$$
\sigma_{k}^{*}=\frac{\left|\sigma_{k}\right|}{\sum_{k=1}^{l}\left|\sigma_{k}\right|} \text {. }
$$

Finally, the optimal attribute weight is obtained as follows:

$$
\mathbf{w}^{*}=\sum_{k=1}^{l} \sigma_{k}^{*} w_{k}^{T} \text {. }
$$

3.2. Determination of Time Series Weights. The impacts of different time points in air combat target data on threat assessment are different. To make a comprehensive and objective evaluation of the dynamic air combat situation, calculating the weights of different time series is a prerequisite. The air combat process is further along at the current time, and thus the measured target threat assessment information is less crucial. Thus, the inverse Poisson distribution method is adopted to calculate the time series weight vector $\psi=\left(\psi_{1}, \psi_{2}, \ldots, \psi_{k}, \ldots, \psi_{l}\right) . \psi$ of $l$ times can be calculated as follows:

$$
\psi_{k}=\frac{k !}{\phi^{k}} \times\left(\sum_{k=1}^{l} \frac{k !}{\phi^{k}}\right)^{-1},
$$

where $\psi_{\mathrm{k}} \geq 0, \sum_{k=1}^{l} \psi_{k}=1$, and $0<\phi<2$.

\section{Proposed Dynamic Target Threat Assessment Method}

4.1. Threat Assessment Index System. Considering the combat capabilities and attack intentions of incoming targets, the air target assessment system is shown in Figure 1.

\subsubsection{Target Combat Capabilities.}

(1) Target Type. The degrees of the threats of different types of targets are completely different, and the degrees of the threats in descending order are as follows: missile, fighter, bomber, Armed helicopter, and early warning aircraft.

(2) Maneuvering Ability. The stronger the targe's maneuverability, the lower the hit rate of air defense weapons against it and the greater the degree of the threat.

\subsubsection{Target Attack Intentions.}

(1) Target Velocity. The faster the target's flight speed, the shorter the reaction time for the commander, the greater the lethality of this target to the target we want to protect, and the higher the degree of the threat.

(2) Target Height. The higher the altitude of the air target is, the more time we can take to form corresponding measures against the target, and thus the lower its threat. The lower the target height is, the higher the attack rate, and the higher the corresponding threat.

(3) Route Shortcut. The air route shortcut of the target refers to the vertical distance from the point protected by our side to the projected extension line of the instantaneous velocity of the air raid target on the horizontal plane. The smaller the air route shortcut, the higher the degree of the threat of the target.

(4) Target Distance. Target distance refers to the distance between the target and the boundary of the air defense area, reflecting the enemy's attack attempt and the possibility of achieving an attack. The smaller the target distance, the higher the degree of the target threat and the greater the corresponding degree of membership.

(5) Target Arrival Time. The target arrival time refers to the time when the target reaches the near boundary of the air defense fire launch zone. The smaller the value, the shorter the preparation time of the weapon system and tactical decision and the greater the threat to us.

4.2. Dynamic Threat Assessment Method Based on IVIFS, Game Theory, and ERM. To provide an effective auxiliary decision-making method, which can help the commander to make the correct decision, a novel dynamic threat assessment method based on the IVIFS, game theory, and the ERM 


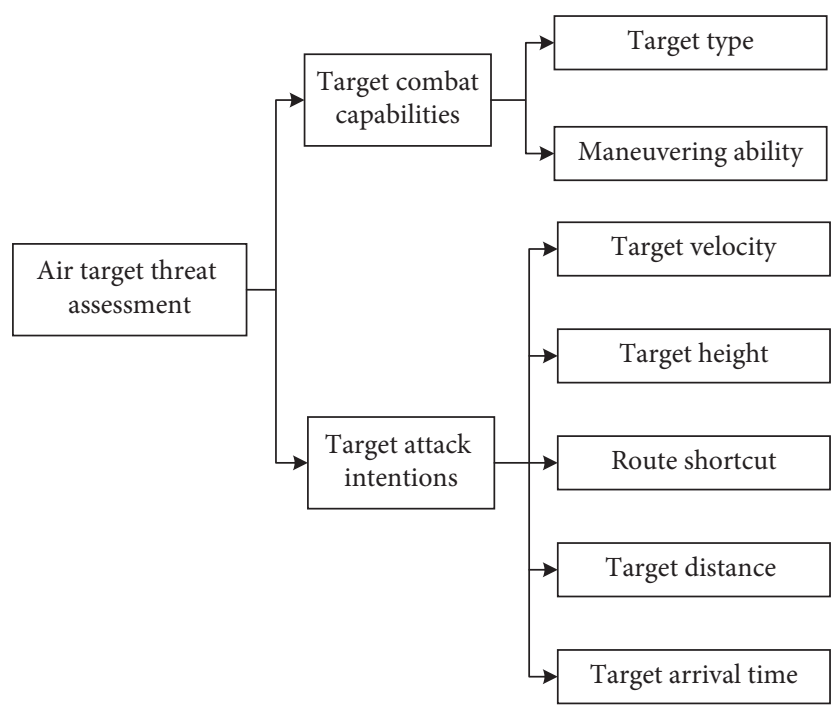

FIgURE 1: Air target threat assessment index system.

is proposed. The process for the proposed method is shown in Figure 2.

Step 1 . The determination of the initial decision matrix air targets set $X=\left\{x_{1}, x_{2}, \ldots, x_{m}\right\}$ includes $m$ targets to be evaluated, and the attribute set $C=\left\{c_{1}, c_{2}, \ldots, c_{n}\right\}$ consists of $n$ attributes. Denote the decision matrix $D$ at time $t_{k}(1 \leq k \leq l)$ as follows:

$$
\begin{array}{rllllll} 
& c_{1} & c_{2} & & & c_{n} \\
x_{1} & \left\langle\left(\mu_{11 L}^{(k)}, \mu_{11 U}^{(k)}\right),\left(v_{11 L}^{(k)}, v_{11 U}^{(k)}\right)\right\rangle & \left\langle\left(\mu_{12 L}^{(k)}, \mu_{12 U}^{(k)}\right),\left(v_{12 L}^{(k)}, v_{12 U}^{(k)}\right)\right\rangle & \cdots & \left\langle\left(\mu_{1 n L}^{(k)}, \mu_{1 n U}^{(k)}\right),\left(v_{1 n L}^{(k)}, v_{1 n U}^{(k)}\right)\right\rangle \\
D_{k}=x_{2} & \left\langle\left(\mu_{21 L}^{(k)}, \mu_{21 U}^{(k)}\right),\left(v_{21 L}^{(k)}, v_{21 U}^{(k)}\right)\right\rangle & \left\langle\left(\mu_{22 L}^{(k)}, \mu_{22 U}^{(k)}\right),\left(v_{22 L}^{(k)}, v_{22 U}^{(k)}\right)\right\rangle & \cdots & \left\langle\left(\mu_{2 n L}^{(k)}, \mu_{2 n U}^{(k)}\right),\left(v_{2 n L}^{(k)}, v_{2 n U}^{(k)}\right)\right\rangle \\
\vdots & \vdots & \vdots & & \vdots \\
x_{m} & \left\langle\left(\mu_{m 1 L}^{(k)}, \mu_{m 1 U}^{(k)}\right),\left(v_{m 1 L}^{(k)}, v_{m 1 U}^{(k)}\right)\right\rangle & \left\langle\left(\mu_{m 2 L}^{(k)}, \mu_{m 2 U}^{(k)}\right),\left(v_{m 2 L}^{(k)}, v_{m 2 U}^{(k)}\right)\right\rangle & \cdots & \left\langle\left(\mu_{m n L}^{(k)}, \mu_{m n U}^{(k)}\right),\left(v_{m n L}^{(k)}, v_{m n U}^{(k)}\right)\right\rangle
\end{array} .
$$

Step 2. Calculate the index weight $\mathbf{w}\left(t_{k}\right)$ at different times and obtain the optimal index weight $\mathbf{w}^{*}$ as follows:

$$
\mathbf{w}^{*}=\left(\mathrm{w}_{1}^{*}, \mathrm{w}_{2}^{*}, \ldots, \mathrm{w}_{n}^{*}\right) .
$$

Step 3. Aggregate the initial decision matrix based on the ERM and the optimal index weights to the dynamic decision matrix.

Step 3.1. Let

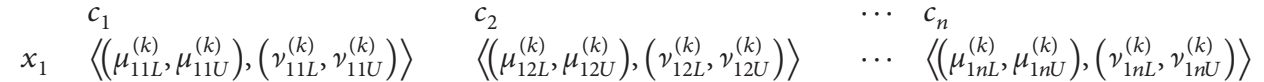

$$
\begin{aligned}
& D_{k}=x_{2} \quad\left\langle\left(\mu_{21 L}^{(k)}, \mu_{21 U}^{(k)}\right),\left(v_{21 L}^{(k)}, v_{21 U}^{(k)}\right)\right\rangle \quad\left\langle\left(\mu_{22 L}^{(k)}, \mu_{22 U}^{(k)}\right),\left(v_{22 L}^{(k)}, v_{22 U}^{(k)}\right)\right\rangle \quad \cdots \quad\left\langle\left(\mu_{2 n L}^{(k)}, \mu_{2 n U}^{(k)}\right),\left(v_{2 n L}^{(k)}, v_{2 n U}^{(k)}\right)\right\rangle \\
& \begin{array}{cccccc}
\vdots & \vdots & \vdots & \vdots \\
x_{m} & \left\langle\left(\mu_{m 1 L}^{(k)}, \mu_{m 1 U}^{(k)}\right),\left(v_{m 1 L}^{(k)}, v_{m 1 U}^{(k)}\right)\right\rangle & \left\langle\left(\mu_{m 2 L}^{(k)}, \mu_{m 2 U}^{(k)}\right),\left(v_{m 2 L}^{(k)}, v_{m 2 U}^{(k)}\right)\right\rangle & \cdots & \left\langle\left(\mu_{m n L}^{(k)}, \mu_{m n U}^{(k)}\right),\left(v_{m n L}^{(k)}, v_{m n U}^{(k)}\right)\right\rangle
\end{array}
\end{aligned}
$$

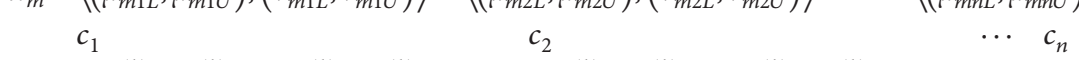

$$
\begin{aligned}
& x_{1}\left\langle\left(\beta_{1,11 L}^{(k)}, \beta_{1,11 U}^{(k)}\right),\left(\beta_{2,11 L}^{(k)}, \beta_{2,11 U}^{(k)}\right)\right\rangle \quad\left\langle\left(\beta_{1,12 L}^{(k)}, \beta_{1,12 U}^{(k)}\right),\left(\beta_{2,12 L}^{(k)}, \beta_{2,12 U}^{(k)}\right)\right\rangle \quad \ldots \quad\left\langle\left(\beta_{1,1 n L}^{(k)}, \beta_{1,1 n U}^{(k)}\right),\left(\beta_{2,1 n L}^{(k)}, \beta_{2,1 n U}^{(k)}\right)\right\rangle \\
& =x_{2}\left\langle\left(\beta_{1,21 L}^{(k)}, \beta_{1,21 U}^{(k)}\right),\left(\beta_{2,21 L}^{(k)}, \beta_{2,21 U}^{(k)}\right)\right\rangle \quad\left\langle\left(\beta_{1,22 L}^{(k)}, \beta_{1,22 U}^{(k)}\right),\left(\beta_{2,22 L}^{(k)}, \beta_{2,22 U}^{(k)}\right)\right\rangle \quad \cdots \quad\left\langle\left(\beta_{1,2 n L}^{(k)}, \beta_{1,2 n U}^{(k)}\right),\left(\beta_{2,2 n L}^{(k)}, \beta_{2,2 n U}^{(k)}\right)\right\rangle,
\end{aligned}
$$

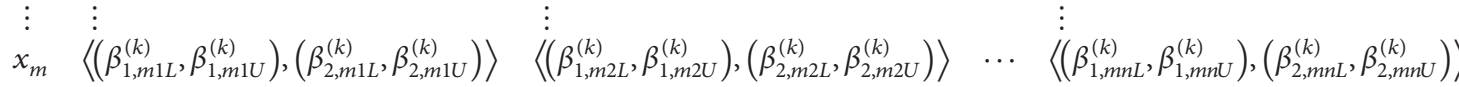




$$
\begin{array}{rlllll} 
& t_{1} & t_{2} & & \\
x_{1} & \left\langle\left(\beta_{L, 1}\left(x_{1}\right), \beta_{U, 1}\left(x_{1}\right)\right),\left(\beta_{L, 2}\left(x_{1}\right), \beta_{U, 2}\left(x_{1}\right)\right)\right\rangle & \left\langle\left(\beta_{L, 1}\left(x_{1}\right), \beta_{U, 1}\left(x_{1}\right)\right),\left(\beta_{L, 2}\left(x_{1}\right), \beta_{U, 2}\left(x_{1}\right)\right)\right\rangle & \cdots & \left\langle\left(\beta_{L, 1}\left(x_{1}\right), \beta_{U, 1}\left(x_{1}\right)\right),\left(\beta_{L, 2}\left(x_{1}\right), \beta_{U, 2}\left(x_{1}\right)\right)\right\rangle \\
Y_{k}=x_{2} & \left\langle\left(\beta_{L, 1}\left(x_{2}\right), \beta_{U, 1}\left(x_{2}\right)\right),\left(\beta_{L, 2}\left(x_{2}\right), \beta_{U, 2}\left(x_{2}\right)\right)\right\rangle & \left\langle\left(\beta_{L, 1}\left(x_{2}\right), \beta_{U, 1}\left(x_{2}\right)\right),\left(\beta_{L, 2}\left(x_{2}\right), \beta_{U, 2}\left(x_{2}\right)\right)\right\rangle & \cdots & \left\langle\left(\beta_{L, 1}\left(x_{2}\right), \beta_{U, 1}\left(x_{2}\right)\right),\left(\beta_{L, 2}\left(x_{2}\right), \beta_{U, 2}\left(x_{2}\right)\right)\right\rangle \\
\vdots & \vdots & \vdots & & \vdots \\
x_{m} & \left\langle\left(\beta_{L, 1}\left(x_{m}\right), \beta_{U, 1}\left(x_{m}\right)\right),\left(\beta_{L, 2}\left(x_{m}\right), \beta_{U, 2}\left(x_{m}\right)\right)\right\rangle & \left\langle\left\langle\left(\beta_{L, 1}\left(x_{m}\right), \beta_{U, 1}\left(x_{m}\right)\right),\left(\beta_{L, 2}\left(x_{m}\right), \beta_{U, 2}\left(x_{m}\right)\right)\right\rangle\right\rangle & \cdots & \left\langle\left\langle\left(\beta_{L, 1}\left(x_{m}\right), \beta_{U, 1}\left(x_{m}\right)\right),\left(\beta_{L, 2}\left(x_{m}\right), \beta_{U, 2}\left(x_{m}\right)\right)\right\rangle\right\rangle
\end{array} .
$$

In equation (23), $\left\langle\left(\beta_{1, i j L}^{(k)}, \beta_{1, i j U}^{(k)}\right),\left(\beta_{2, i j L}^{(k)}, \beta_{2, i j \mathrm{U}}^{(k)}\right)\right\rangle \mathrm{de}$ notes the degrees of belief of the decision matrix at time $t_{k}$ with respect to attribute $c_{j}$ of target $x_{i}$ regarding the evaluation grades $H_{1}$ and $H_{2}$, respectively. $H_{1}$ represents completely satisfying the fuzzy concept "threaten," $\mathrm{H}_{2}$ represents not satisfying the fuzzy concept "threaten," and $H$ represents the evaluation grade of indeterminacy (uncertainty). Step 3.2. Transform the degree of belief $\left\langle\left(\beta_{1, i j L}^{(k)}\right.\right.$, $\left.\left.\beta_{1, i j U}^{(k)}\right),\left(\beta_{2, i j L}^{(k)}, \beta_{2, i j U}^{(k)}\right)\right\rangle$ at time $t_{k}$ into the basic probability mass $\left\langle\left(m_{1, i j L}^{(k)}, m_{1, i j U}^{(k)}\right),\left(m_{2, i j L}^{(k)}, m_{2, i j U}^{(k)}\right)\right\rangle$, which is shown as follows:

$$
\begin{aligned}
{\left[m_{L, q j}^{(k)}\left(x_{i}\right), m_{U, q j}^{(k)}\left(x_{i}\right)\right]=} & w^{*} \times\left[\beta_{q j L}^{(k)}\left(x_{i}\right), \beta_{q j U}^{(k)}\left(x_{i}\right)\right], \\
{\left[m_{L, H j}^{(k)}\left(x_{i}\right), m_{U, H j}^{(k)}\left(x_{i}\right)\right]=} & {\left[\left(1-w^{*}\right)+\right] } \\
& \cdot w^{*}\left(1-\sum_{q=1}^{2} \beta_{q j U}^{(k)}\left(x_{i}\right)\left(1-w^{*}\right)\right. \\
& \left.\left.+w^{*}\left(1-\sum_{q=1}^{2} \beta_{q j L}^{(k)}\left(x_{i}\right)\right)\right)\right] .
\end{aligned}
$$

Step 3.3. Compute the combined probability mass Note that

$$
\begin{aligned}
{\left[m_{L, I(1)}^{(k)}\left(x_{i}\right), m_{U, I(1)}^{(k)}\left(x_{i}\right)\right] } & =\left[m_{L, q 1}^{(k)}\left(x_{i}\right), m_{U, q 1}^{(k)}\left(x_{i}\right)\right](q=1,2) \\
{\left[m_{L, H I(1)}^{(k)}\left(x_{i}\right), m_{U, H I(1)}^{(k)}\left(x_{i}\right)\right] } & =\left[m_{L, H 1}^{(k)}\left(x_{i}\right), m_{U, H 1}^{(k)}\left(x_{i}\right)\right] .
\end{aligned}
$$

The combined probability mass can be generated by combining the basic probability masses.

$$
\begin{aligned}
& {\left[m_{L, q I(y)}^{(k)}\left(x_{i}\right), m_{U, q I(y)}^{(k)}\left(x_{i}\right)\right]=} \\
& {\left[\lambda _ { L , I ( y ) } ^ { ( k ) } ( x _ { i } ) \left(m_{L, q I(y-1)}^{(k)}\left(x_{i}\right) m_{U, q y}^{(k)}\left(x_{i}\right)\right.\right.} \\
& \left.\quad+m_{U, q I(y-1)}^{(k)}\left(x_{i}\right) m_{L, H y}^{(k)}\left(x_{i}\right)+m_{U, H I(y-1)}^{(k)}\left(x_{i}\right) m_{U, q y}^{(k)}\left(x_{i}\right)\right), \\
& \lambda_{U, I(y)}^{(k)}\left(x_{i}\right)\left(m_{U, q I(y-1)}^{(k)}\left(x_{i}\right) m_{L, q y}^{(k)}\left(x_{i}\right)\right. \\
& \left.\left.+m_{U, q I(y-1)}^{(k)}\left(x_{i}\right) m_{U, H y}^{(k)}\left(x_{i}\right)+m_{U, H I(y-1)}^{(k)}\left(x_{i}\right) m_{L, q y}^{(k)}\left(x_{i}\right)\right)\right], \\
& {\left[m_{L, H I(y)}^{(k)}\left(x_{i}\right), m_{U, H I(y)}^{(k)}\left(x_{i}\right)\right]} \\
& =\left[\lambda_{L, I(y)}^{(k)}\left(x_{i}\right) m_{L, H I(y-1)}^{(k)}\left(x_{i}\right) m_{L, H y}^{(k)}\left(x_{i}\right),\right. \\
& \left.\lambda_{U, I(y)}^{(k)}\left(x_{i}\right) m_{U, H I(y-1)}^{(k)}\left(x_{i}\right) m_{U, H y}^{(k)}\left(x_{i}\right)\right],
\end{aligned}
$$

where

$$
\lambda_{L, I(y)}^{(k)}\left(x_{i}\right)=\left(1-\sum_{\substack { t=1 \\
\begin{subarray}{c}{g=1 \\
y \neq t{ t = 1 \\
\begin{subarray} { c } { g = 1 \\
y \neq t } }\end{subarray}}^{2} m_{L, t I(y-1)}^{(k)}\left(x_{i}\right) m_{L, g y}^{(k)}\left(x_{i}\right)\right)
$$

$, 2 \leq y \leq n, 1 \leq q \leq 2$, and, $1 \leq i \leq m$,

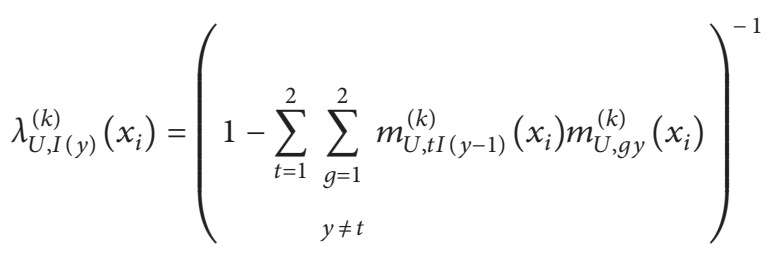$$
, 2 \leq y \leq n, 1 \leq q \leq 2 \text {, and, } 1 \leq i \leq m .
$$

Step 3.4. Aggregate the evaluated values of the attributes of target $X_{m}$ to get the degree of belief $\beta_{\mathrm{L}, H}\left(x_{i}\right)$ of target $X_{m}$ regarding the evaluation grade and the degree of belief produced by unknown information, respectively, as follows:

$$
\begin{aligned}
& {\left[\beta_{L, q}^{(k)}\left(x_{i}\right), \beta_{U, q}^{(k)}\left(x_{i}\right)\right]=\left[\left(1-\beta_{L, H}^{(k)}\left(x_{i}\right)\right) \frac{m_{L, q I(n)}^{(k)}\left(x_{i}\right)}{1-m_{L, q H I(n)}^{(k)}\left(x_{i}\right)},\right.} \\
& \left.\left(1-\beta_{U, H}^{(k)}\left(x_{i}\right)\right) \frac{m_{U, q I(n)}^{(k)}\left(x_{i}\right)}{1-m_{U, q H I(n)}^{(k)}\left(x_{i}\right)}\right], \\
& {\left[\beta_{L, H}^{(k)}\left(x_{i}\right), \beta_{U, H}^{(k)}\left(x_{i}\right)\right]=\left[\sum_{j=1}^{n} w^{*}\left(1-\sum_{q=1}^{2} \beta_{U, q j}^{(k)}\left(x_{i}\right)\right),\right.} \\
& \left.\sum_{j=1}^{n} w^{*}\left(1-\sum_{q=1}^{2} \beta_{L, q j}^{(k)}\left(x_{i}\right)\right)\right],
\end{aligned}
$$

where

$$
\begin{aligned}
& \sum_{q=1}^{2} \beta_{L, q}^{(k)}\left(x_{i}\right)+\beta_{L, H}^{(k)}\left(x_{i}\right)=1, \quad 1 \leq i \leq m, \text { and } 1 \leq q \leq 2, \\
& \sum_{q=1}^{2} \beta_{U, q}^{(k)}\left(x_{i}\right)+\beta_{U, H}^{(k)}\left(x_{i}\right)=1, \quad 1 \leq i \leq m, \text { and } 1 \leq q \leq 2 .
\end{aligned}
$$

Step 3.5. The aggregated value of the evaluated values of the attributes of alternative $x_{m}$ is represented by 
an IVIFS $\left\langle\left(\beta_{L, 1}^{(k)}\left(x_{i}\right), \beta_{U, 1}^{(k)}\left(x_{i}\right)\right),\left(\beta_{L, 2}^{(k)}\left(x_{i}\right), \beta_{U, 2}^{(k)}\left(x_{i}\right)\right)\right\rangle$. The dynamic decision matrix $Y_{k}$ is obtained as equation (24).

Step 4. Calculate the time series weight $\psi_{\mathrm{k}}, 1 \leq k \leq l$.

Step 5. Aggregate the dynamic decision matrix $Y_{k}$ based on the ERM and the time series weights to the final decision matrix $Z_{m}$.

Step 5.1. Transform the degree of belief $\left\langle\left(\beta_{L, 1}^{(k)}\left(x_{i}\right), \beta_{U, 1}^{(k)}\left(x_{i}\right)\right),\left(\beta_{L, 2}^{(k)}\left(x_{i}\right), \beta_{U, 2}^{(k)}\left(x_{i}\right)\right)\right\rangle$ into the basic probability mass $\left\langle\left(m_{1, i j L}^{(k)}, m_{1, i j U}^{(k)}\right),\left(m_{2, i j L}^{(k)}, m_{2, i j U}^{(k)}\right)\right\rangle$, as follows:

$$
\begin{aligned}
& {\left[m_{L, q j}\left(x_{i}\right), m_{U, q j}\left(x_{i}\right)\right]=\left[\psi_{k} \beta_{L q}\left(x_{i}\right), \psi_{k} \beta_{U q}\left(x_{i}\right)\right],} \\
& {\left[m_{L, H j}\left(x_{i}\right), m_{U, H j}\left(x_{i}\right)\right]=} \\
& {\left[1-\sum_{q=1}^{2} m_{L, q j}\left(x_{i}\right), 1-\sum_{q=1}^{2} m_{U, q j}\left(x_{i}\right)\right] .}
\end{aligned}
$$

Step 5.2. Compute the combined probability mass. Note that $\left[m_{L, I(1)}\left(x_{i}\right), m_{U, I(1)}\left(x_{i}\right)\right]=$ $\left[m_{L, q 1}\left(x_{i}\right), m_{U, q 1}\left(x_{i}\right)\right]$ and

$\left[m_{L, H I(1)}\left(x_{i}\right), m_{U, H I(1)}\left(x_{i}\right)\right]=\left[m_{L, H 1}\left(x_{i}\right), m_{U, H 1}\left(x_{i}\right)\right]$.

The combined probability mass can be generated by combining the basic probability masses as described as follows:

$$
\begin{aligned}
& {\left[m_{L, q I(y)}\left(x_{i}\right), m_{U, q I(y)}\left(x_{i}\right)\right]=} \\
& \quad\left[\lambda _ { L , I ( y ) } ( x _ { i } ) \left(m_{L, q I(y-1)}\left(x_{i}\right) m_{U, q y}\left(x_{i}\right)\right.\right. \\
& +m_{U, q I(y-1)}\left(x_{i}\right) m_{L, H y}\left(x_{i}\right) \\
& \left.+m_{U, H I(y-1)}\left(x_{i}\right) m_{L, q y}\left(x_{i}\right)\right) \\
& \quad \lambda_{U, I(y)}\left(x_{i}\right)\left(m_{U, q I(y-1)}\left(x_{i}\right) m_{L, q y}\left(x_{i}\right)\right. \\
& +m_{U, q I(y-1)}\left(x_{i}\right) m_{U, H y}\left(x_{i}\right) \\
& \left.\left.+m_{U, H I(y-1)}\left(x_{i}\right) m_{L, q y}\left(x_{i}\right)\right)\right], \\
& \quad\left[m_{L, H I(y)}\left(x_{i}\right), m_{U, H I(y)}\left(x_{i}\right)\right]= \\
& {\left[\lambda_{L, I(y)}\left(x_{i}\right) m_{L, H I(y-1)}\left(x_{i}\right) m_{L, H y}\left(x_{i}\right),\right.} \\
& \left.\lambda_{U, I(y)}\left(x_{i}\right) m_{U, H I(y-1)}\left(x_{i}\right) m_{U, H y}\left(x_{i}\right)\right],
\end{aligned}
$$

where

$$
\begin{aligned}
\lambda_{L, I(y)}\left(x_{i}\right) & =\left(1-\sum_{t=1}^{2} \sum_{\substack{g=1 \\
y \neq t}}^{2} m_{L, t I(y-1)}\left(x_{i}\right) m_{L, g y}\left(x_{i}\right)\right)^{-1} \\
2 & \leq y \leq l, 1 \leq q \leq 2, \text { and }, 1 \leq i \leq m, \\
\lambda_{U, I(y)}\left(x_{i}\right) & =\left(1-\sum_{t=1}^{2} \sum_{\substack{g=1 \\
y \neq t}}^{2} m_{U, t I(y-1)}\left(x_{i}\right) m_{U, g y}\left(x_{i}\right)\right)^{-1} \\
2 & \leq y \leq l, 1 \leq q \leq 2, \text { and }, 1 \leq i \leq m .
\end{aligned}
$$

Step 5.3. Aggregate the evaluated values of the attributes of target $X_{m}$ to get the degree of belief $\beta_{L, H}\left(x_{i}\right)$ of target $X_{m}$ regarding the evaluation grade and the degree of belief produced by unknown information, respectively, as follows:

$$
\begin{aligned}
& {\left[\beta_{L, q}\left(x_{i}\right), \beta_{U, q}\left(x_{i}\right)\right]=} \\
& {\left[\left(1-\beta_{L, H}\left(x_{i}\right)\right) \frac{m_{L, q I(n)}\left(x_{i}\right)}{1-m_{L, q H I}(n)}\left(x_{i}\right)\right.} \\
& \left.\left(1-\beta_{U, H}\left(x_{i}\right)\right) \frac{m_{U, q I(n)}\left(x_{i}\right)}{1-m_{U, q H I(n)}\left(x_{i}\right)}\right], \\
& {\left[\beta_{L, H}\left(x_{i}\right), \beta_{U, H}\left(x_{i}\right)\right]=\left[\sum_{j=1}^{n} \psi_{k}\left(1-\sum_{q=1}^{2} \beta_{L, q j}\left(x_{i}\right)\right)\right]} \\
& \sum_{j=1}^{n} \psi_{k}\left(1-\sum_{q=1}^{2} \beta_{U, q j}\left(x_{i}\right)\right),
\end{aligned}
$$

where

$$
\begin{array}{ll}
\sum_{q=1}^{2} \beta_{L, q}\left(x_{i}\right)+\beta_{L, H}\left(x_{i}\right)=1, & 1 \leq i \leq m, \text { and } 1 \leq q \leq 2, \\
\sum_{q=1}^{2} \beta_{U, q}\left(x_{i}\right)+\beta_{U, H}\left(x_{i}\right)=1, & 1 \leq i \leq m, \text { and } 1 \leq q \leq 2 .
\end{array}
$$

Step 5.4. The aggregated value of the evaluated values of the attributes of alternative $x_{m}$ is represented by an $\operatorname{IVIFS}\left\langle\left(\beta_{L, 1}\left(x_{i}\right), \beta_{U, 1}\left(x_{i}\right)\right),\left(\beta_{L, 2}\left(x_{i}\right), \beta_{U, 2}\left(x_{i}\right)\right)\right\rangle$. The final decision matrix $Z_{m}$ is obtained as follows:

$$
\begin{array}{cc}
x_{1} & \left\langle\left(\beta_{L, 1}\left(x_{1}\right), \beta_{U, 1}\left(x_{1}\right)\right),\left(\beta_{L, 2}\left(x_{1}\right), \beta_{U, 2}\left(x_{1}\right)\right)\right\rangle \\
Z_{2} & \left\langle\left(\beta_{L, 1}\left(x_{2}\right), \beta_{U, 1}\left(x_{2}\right)\right),\left(\beta_{L, 2}\left(x_{2}\right), \beta_{U, 2}\left(x_{2}\right)\right)\right\rangle \\
\vdots & \vdots \\
x_{m} & \left\langle\left(\beta_{L, 1}\left(x_{m}\right), \beta_{U, 1}\left(x_{m}\right)\right),\left(\beta_{L, 2}\left(x_{m}\right), \beta_{U, 2}\left(x_{m}\right)\right)\right\rangle
\end{array} .
$$

Step 6. Calculate the accuracy function value of each target according to equation (2). The higher the score of the accuracy function, the greater the target threat. Thus, the evaluation ranking result is acquired. 


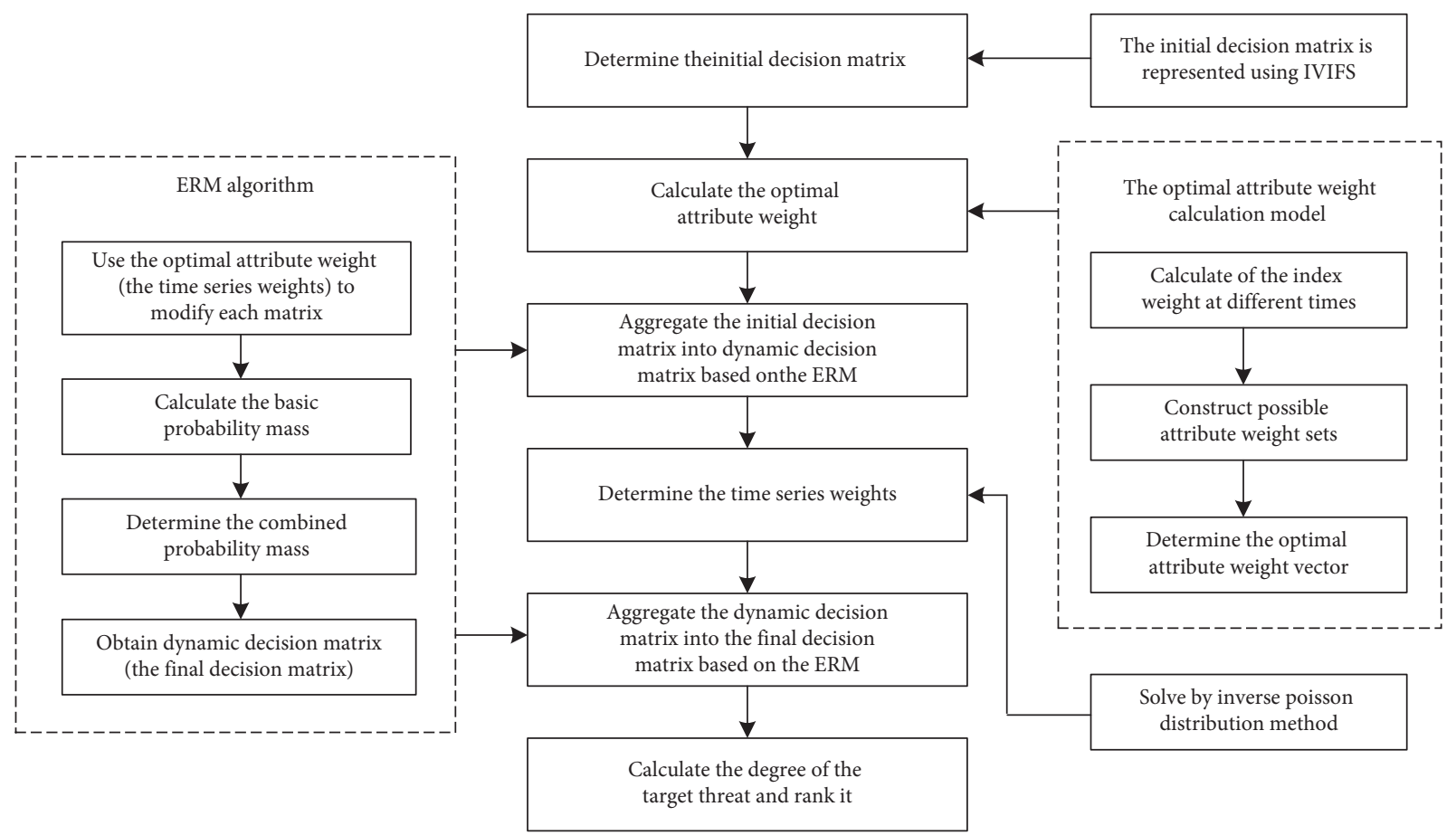

FIGURE 2: Algorithm flow chart of the proposed air target threat assessment method.

\section{Numerical Examples and Discussion}

\subsection{Numerical Examples.}

Step 1. The initial decision matrix is determined as follows.

Our side finds five air targets through detection equipment. The air target set $X=\left\{x_{1}, x_{2}, \ldots, x_{5}\right\}$ corresponds to bomber, fighter, missile, early warning aircraft, Armed helicopter $\}$. The attribute set $C=\left\{c_{1}, c_{2}, \ldots, c_{7}\right\}$ consists of seven attributes, which correspond to \{target type, target arrival time, target height, target distance, route shortcut, target velocity, maneuvering ability\}. The IVIFS matrix of the air target at three time points $t_{1}, t_{2}$, and $t_{3}$ is as shown in Tables 1-3, respectively.

Step 2. According to Table 1 to Table 3, the attribute weights and the optimal index weight at each time are as Table 4.

Step 3. Based on the IVIFS assessment information and the optimal index weight, the dynamic decision matrix $Y_{k}$ is obtained as Table 5 .

Step 4. The time series weight is obtained when $\phi=1.5$ as follows:

$$
\psi=\{0.2000,0.2667,0.5333\}
$$

Step 5. Based on dynamic decision matrix and the time series weight, the final decision matrix $Z_{m}$ is obtained as follows:

$$
\begin{aligned}
& \left(\left[\beta_{1 L}\left(x_{1}\right), \beta_{1 U}\left(x_{1}\right)\right],\left[\beta_{2 L}\left(x_{1}\right), \beta_{2 U}\left(x_{1}\right)\right]\right)= \\
& ([0.67260 .7687],[0.08270 .1455]), \\
& \left(\left[\beta_{1 L}\left(x_{2}\right), \beta_{1 U}\left(x_{2}\right)\right],\left[\beta_{2 L}\left(x_{2}\right), \beta_{2 U}\left(x_{2}\right)\right]\right)= \\
& ([0.58300 .6765],[0.09250 .1532]), \\
& \left(\left[\beta_{1 L}\left(x_{3}\right), \beta_{1 U}\left(x_{3}\right)\right],\left[\beta_{2 L}\left(x_{3}\right), \beta_{2 U}\left(x_{3}\right)\right]\right)= \\
& ([0.74920 .8642],[0.05020 .0872]), \\
& \left(\left[\beta_{1 L}\left(x_{4}\right), \beta_{1 U}\left(x_{4}\right)\right],\left[\beta_{2 L}\left(x_{4}\right), \beta_{2 U}\left(x_{4}\right)\right]\right)= \\
& ([0.46620 .5605],[0.15810 .2488]), \\
& \left(\left[\beta_{1 L}\left(x_{5}\right), \beta_{1 U}\left(x_{5}\right)\right],\left[\beta_{2 L}\left(x_{5}\right), \beta_{2 U}\left(x_{5}\right)\right]\right)= \\
& ([0.69650 .7876],[0.08110 .1257]) .
\end{aligned}
$$

Step 6. The degrees of the target threats are sorted by the accuracy function.

$$
\begin{aligned}
& M_{1}\left(\left[\beta_{1 L}\left(x_{1}\right), \beta_{1 U}\left(x_{1}\right)\right],\left[\beta_{2 L}\left(x_{1}\right), \beta_{2 U}\left(x_{1}\right)\right]\right)=0.5554, \\
& M_{2}\left(\left[\beta_{1 L}\left(x_{2}\right), \beta_{1 U}\left(x_{2}\right)\right],\left[\beta_{2 L}\left(x_{2}\right), \beta_{2 U}\left(x_{2}\right)\right]\right)=0.3824, \\
& M_{3}\left(\left[\beta_{1 L}\left(x_{3}\right), \beta_{1 U}\left(x_{3}\right)\right],\left[\beta_{2 L}\left(x_{3}\right), \beta_{2 U}\left(x_{3}\right)\right]\right)=0.6821, \\
& M_{4}\left(\left[\beta_{1 L}\left(x_{4}\right), \beta_{1 U}\left(x_{4}\right)\right],\left[\beta_{2 L}\left(x_{4}\right), \beta_{2 U}\left(x_{4}\right)\right]\right)=0.2302, \\
& M_{5}\left(\left[\beta_{1 L}\left(x_{5}\right), \beta_{1 U}\left(x_{5}\right)\right],\left[\beta_{2 L}\left(x_{5}\right), \beta_{2 U}\left(x_{5}\right)\right]\right)=0.5875 .
\end{aligned}
$$


TABLE 1: Assessment information of targets $x_{1}-x_{5}$ at time $t_{1}$.

\begin{tabular}{cccccccc}
\hline Target & $c_{1}$ & $c_{2}$ & $c_{3}$ & $c_{4}$ & $c_{5}$ & $c_{6}$ \\
\hline \multirow{2}{*}{$x_{1}$} & $<[0.75,0.85]$ & $<[0.48,0.58]$ & $<[0.70,0.75]$ & $<[0.50,0.55]$ & $<[0.40,0.45]$ & $<[0.55,0.60]$ & $<[0.55,0.65]$ \\
& {$[0.05,0.10]>$} & {$[0.10,0.20]>$} & {$[0.05,0.12]>$} & {$[0.05,0.15]>$} & {$[0.30,0.40]>$} & {$[0.20,0.30]>$} & {$[0.05,0.15]>$} \\
\hline \multirow{2}{*}{$x_{2}$} & $<[0.65,0.75]$, & $<[0.45,0.55]$ & $<[0.65,0.72]$ & $<[0.45,0.55]$ & $<[0.65,0.70]$ & $<[0.55,0.60]$ & $<[0.55,0.60]$ \\
& {$[0.15,0.25]>$} & {$[0.20,0.30]>$} & {$[0.12,0.21]>$} & {$[0.15,0.25]>$} & {$[0.15,0.25]>$} & {$[0.22,0.37]>$} & {$[0.10,0.20]>$} \\
\multirow{2}{*}{$x_{3}$} & $<[0.85,0.95]$ & $<[0.30,0.40]$ & $<[0.55,0.65]$ & $<[0.5,0.6]$ & $<[0.70,0.75]$ & $<[0.80,0.85]$ & $<[0.70,0.80]$ \\
& {$[0.01,0.05]>$} & {$[0.40,0.50]>$} & {$[0.20,0.30]>$} & {$[0.04,0.13]>$} & {$[0.05,0.15]>$} & {$[0.01,0.12]>$} & {$[0.02,0.12]>$} \\
\hline \multirow{2}{*}{$x_{4}$} & $<[0.25,0.35]$ & $<[0.35,0.45]$ & $<[0.45,0.55]$ & $<[0.60,0.70]$ & $<[0.45,0.55]$ & $<[0.35,0.45]$ & $<[0.25,0.35]$ \\
& {$[0.30,0.40]>$} & {$[0.10,0.30]>$} & {$[0.35,0.40]>$} & {$[0.05,0.15]>$} & {$[0.1,0.20]>$} & {$[0.10,0.20]>$} & {$[0.30,0.40]>$} \\
\multirow{2}{*}{$x_{5}$} & $<[0.45,0.55]$ & $<[0.75,0.8]$ & $<[0.80,0.85]$ & $<[0.80,0.85]$ & $<[0.30,0.35]$ & $<[0.35,0.45]$ & $<[0.65,0.70]$ \\
& {$[0.30,0.40]>$} & {$[0.08,0.15]>$} & {$[0.01,0.06]>$} & {$[0.00,0.10]>$} & {$[0.20,0.3]>$} & {$[0.35,0.50]>$} & {$[0.08,0.20]>$} \\
\hline
\end{tabular}

According to $M_{3}>M_{5}>M_{1}>M_{2}>M_{4}$, the ranking result of the target threat assessment is obtained: $x_{3}>x_{5}>x_{1}>x_{2}>x_{4}$. According to the initial decision matrix data shown in Tables $1-3$, the target threat assessment results are consistent with reality.

\subsection{Discussion and Comparative Analysis}

5.2.1. Discussion of Experimental Results. In the dynamic target threat assessment process, the time factor has a great influence on the target threat assessment results. Table 6 shows the sorting results at each different moment.

The final threat ranking of each target is as follows: $x_{3}>x_{5}>x_{1}>x_{2}>x_{4}$. The ranking result of the target threat at the current moment is $0.5694,0.3216,0.7350,0.2389$, 0.6295. The ranking result of each target is $x_{3}>x_{5}>x_{1}>x_{2}>x_{4}$, which is consistent with the multimoment sorting result.

Meanwhile, it can be seen from the target type that missile has the greatest degree of threat, followed by bomber and then fighter plane and helicopter. Early warning aircraft are used to search and monitor targets, and so their attack threat is the weakest. Although the threat of a fighter plane is higher than that of an armed helicopter, it can be seen from the data at multiple times that the fighter planes are in a climbing state, far away from our targets. However, the armed helicopter is in a diving state, close to our target, and so the threat of the armed helicopter is higher than the threat of the fighter. It can also be seen from the simulation results of this paper that the degree of the threat of fighters changes with time and the degree of the threat decreases continuously. Meanwhile, the degree of the threat of helicopters continues to increase. The analysis results are the same as the simulation results, which prove the rationality of the method proposed in this paper.

Using the same simulation data, the data on both sides do not change at $t_{3}$. At $t_{2}$, target $x_{1}$ rapidly accelerates. Its degree of membership for speed changed from [0.6, 0.65] to $[0.95,1]$; the degree of membership of the target arrival time changed to $[0.95,1]$; and the degree of the threat of maneuvering ability reaches $[0.8,0.9]$. The assessment results of the proposed method are $0.5883,0.3820,0.6816,0.2278$, and 0.5877 . The threat order is $x_{3}>x_{1}>x_{5}>x_{2}>x_{4}$. Only using the current degree of target threat results still gives $x_{3}>x_{5}>x_{1}>x_{2}>x_{4}$. It can be seen that although target 1 has a sharp acceleration movement trend, the degree of the target threat has not changed using the single-time threat assessment method; however, the dynamic change process of the target situation can be considered in the threat assessment using the proposed method, making target 1's degree of threat higher, and more reasonable threat assessment results are obtained.

5.2.2. Comparison with Aggregation Operators. To illustrate the superiority of the proposed method, we compare it with the information aggregation method given in $[4,45]$. The IVIFWG operator and IVIFWA operator are used to aggregate the results at different times. Let an IVIFS $\widetilde{A}=\langle(a, b),(c, d)\rangle$. The IVIFWG operator is shown as follows:

$$
\begin{aligned}
& \operatorname{IVIFWG}_{w}\left(\widetilde{A}_{1}, \widetilde{A}_{2}, \ldots, \widetilde{A}_{n}\right)=\prod_{i=1}^{n} \widetilde{A}_{i}^{w_{i}}= \\
& \left\langle\left[\prod_{i=1}^{n} a_{i}^{w_{i}}, \prod_{i=1}^{n} b_{i}^{w_{i}}, 1-\prod_{i=1}^{n}\left(1-c_{i}\right)^{w_{i}}\right],\left[1-\prod_{i=1}^{n}\left(1-d_{i}\right)^{w_{i}}\right]\right\rangle .
\end{aligned}
$$

The IVIFWA operator is shown as follows:

$$
\begin{aligned}
& \operatorname{IVIFWA}_{w}\left(\tilde{A}_{1}, \tilde{A}_{2}, \ldots, \tilde{A}_{n}\right)=\prod_{i=1}^{n} \tilde{A}_{i}^{w_{i}}= \\
& \left\langle\left[1-\prod_{i=1}^{n}\left(1-a_{i}\right)^{w_{i}}, 1-\prod_{i=1}^{n}\left(1-b_{i}\right)^{w_{i}}\right],\left[\prod_{i=1}^{n} c_{j}^{w_{i}}, \prod_{i=1}^{n} d_{i}^{w_{i}}\right]\right\rangle,
\end{aligned}
$$

where $w=\left(w_{1}, w_{2}, \ldots, w_{n}\right)$ is the weight vector of IVIFN $\widetilde{A}_{i}(i=1,2, \ldots, n), 0<w_{i}<1$, and $\sum_{i=1}^{n} w_{i}=1$.

The interval intuitionistic fuzzy values of each target are obtained through equation (2) as Table 7.

In Table 8, the second to sixth columns are the threat values obtained by different methods for different targets. The threat ranking results are given in column 8 . Table 9 shows the uncertainty interval of different methods and the length of the uncertainty interval.

It can be seen from Table 8 that the method of $[4,44]$ and the method proposed in this paper have the same target 
TABLe 2: Assessment information of targets $x_{1}-x_{5}$ at time $t_{2}$.

\begin{tabular}{cccccccc}
\hline Target & $c_{1}$ & $c_{2}$ & $c_{3}$ & $c_{4}$ & $c_{5}$ & $c_{6}$ & $c_{7}$ \\
\hline \multirow{2}{*}{$x_{1}$} & $<[0.75,0.85]$ & $<[0.58,0.68]$ & $<[0.75,0.80]$ & $<[0.55,0.60]$ & $<[0.45,0.50]$ & $<[0.60,0.65]$ & $<[0.60,0.70]$ \\
& {$[0.05,0.10]>$} & {$[0.15,0.20]>$} & {$[0.05,0.15]>$} & {$[0.25,0.35]>$} & {$[0.35,0.45]>$} & {$[0.20,0.30]>$} & {$[0.20,0.30]>$} \\
\hline \multirow{2}{*}{$x_{2}$} & $<[0.65,0.75]$ & $<[0.45,0.55]$ & $<[0.60,0.65]$ & $<[0.40,0.50]$ & $<[0.60,0.70]$ & $<[0.60,0.65]$ & $<[0.60,0.65]$ \\
& {$[0.15,0.25]>$} & {$[0.20,0.30]>$} & {$[0.08,0.12]>$} & {$[0.10,0.19]>$} & $0.10,0.15]>$ & {$[0.22,0.30]>$} & {$[0.10,0.20]>$} \\
\multirow{2}{*}{$x_{3}$} & $<[0.85,0.95]$ & $<[0.35,0.45]$ & $<[0.60,0.70]$ & $<[0.55,0.60]$ & $<[0.80,0.85]$ & $<[0.85,0.90]$ & $<[0.75,0.85]$ \\
& {$[0.01,0.05]>$} & {$[0.40,0.50]>$} & {$[0.10,0.20]>$} & {$[0.10,0.20]>$} & {$[0.10,0.14]>$} & {$[0.01,0.04]>$} & {$[0.08,0.13]>$} \\
\hline \multirow{2}{*}{$x_{4}$} & $<[0.25,0.35]$ & $<[0.45,0.55]$ & $<[0.45,0.55]$ & $<[0.65,0.70]$ & $<[0.55,0.60]$ & $<[0.35,0.45]$ & $<[0.25,0.35]$ \\
& {$[0.30,0.40]>$} & {$[0.15,0.20]>$} & {$[0.25,0.35]>$} & {$[0.10,0.20]>$} & {$[0.15,0.25]>$} & {$[0.20,0.40]>$} & {$[0.30,0.50]>$} \\
\multirow{2}{*}{$x_{5}$} & $<[0.45,0.55]$ & $<[0.80,0.85]$ & $<[0.80,0.85]$ & $<[0.85,0.90]$ & $<[0.35,0.40]$ & $<[0.45,0.55]$ & $<[0.65,0.75]$ \\
& {$[0.30,0.40]>$} & {$[0.10,0.15]>$} & {$[0.00,0.04]>$} & {$[0.00,0.03]>$} & {$[0.10,0.20]>$} & {$[0.15,0.20]>$} & {$[0.05,0.15]>$} \\
\hline
\end{tabular}

TABle 3: Assessment information of targets $x_{1}-x_{5}$ at time $t_{3}$.

\begin{tabular}{cccccccc}
\hline Target & $c_{1}$ & $c_{2}$ & $c_{3}$ & $c_{4}$ & $c_{5}$ & $c_{6}$ & $c_{7}$ \\
\hline \multirow{2}{*}{$x_{1}$} & $<[0.75,0.85]$ & $<[0.60,0.70]$ & $<[0.80,0.85]$ & $<[0.60,0.65]$ & $<[0.55,0.60]$ & $<[0.60,0.68]$ & $<[0.65,0.70]$ \\
& {$[0.05,0.10]>$} & {$[0.10,0.15]>$} & {$[0.05,0.15]>$} & {$[0.10,0.20]>$} & {$[0.20,0.35]>$} & {$[0.20,0.30]>$} & {$[0.10,0.20]>$} \\
\hline \multirow{2}{*}{$x_{2}$} & $<[0.65,0.75]$ & $<[0.40,0.45]$ & $<[0.55,0.60]$ & $<[0.35,0.45]$ & $<[0.50,0.60]$ & $<[0.65,0.70]$ & $<[0.65,0.70]$ \\
& {$[0.15,0.25]>$} & {$[0.20,0.28]>$} & {$[0.10,0.15]>$} & {$[0.10,0.20]>$} & {$[0.10,0.14]>$} & {$[0.10,0.20]>$} & {$[0.08,0.13]>$} \\
\multirow{2}{*}{$x_{3}$} & $<[0.85,0.95]$ & $<[0.45,0.55]$ & $<[0.65,0.75]$ & $<[0.75,0.85]$ & $<[0.85,0.95]$ & $<[0.90,0.95]$ & $<[0.85,0.90]$ \\
& {$[0.01,0.05]>$} & {$[0.30,0.40]>$} & {$[0.15,0.23]>$} & {$[0.04,0.14]>$} & {$[0.00,0.02]>$} & {$[0.01,0.12]>$} & {$[0.02,0.07]>$} \\
\multirow{2}{*}{$x_{4}$} & $<[0.25,0.35]$ & $<[0.55,0.65]$ & $<[0.50,0.55]$ & $<[0.70,0.75]$ & $<[0.60,0.65]$ & $<[0.40,0.47]$ & $<[0.25,0.35]$ \\
& {$[0.30,0.40]>$} & {$[0.01,0.03]>$} & {$[0.25,0.33]>$} & {$[0.10,0.20]>$} & {$[0.15,0.20]>$} & {$[0.10,0.20]>$} & {$[0.25,0.35]>$} \\
\multirow{2}{*}{$x_{5}$} & $<[0.45,0.55]$ & $<[0.85,0.90]$ & $<[0.85,0.90]$ & $<[0.85,0.90]$ & $<[0.40,0.45]$ & $<[0.55,0.60]$ & $<[0.75,0.85]$ \\
& {$[0.30,0.40]>$} & {$[0.02,0.08]>$} & {$[0.01,0.04]>$} & {$[0.01,0.04]>$} & {$[0.35,0.40]>$} & {$[0.30,0.40]>$} & {$[0.02,0.08]>$} \\
\hline
\end{tabular}

TABLE 4: The attribute weights at each time.

\begin{tabular}{lcccccr}
\hline Time & $c_{1}$ & $c_{2}$ & $c_{3}$ & $c_{4}$ & $c_{5}$ & $c_{6}$ \\
\hline$w\left(t_{1}\right)$ & 0.1580 & 0.1170 & 0.1701 & 0.1686 & 0.1161 & 0.1190 \\
$w\left(t_{2}\right)$ & 0.1461 & 0.1193 & 0.1697 & 0.1536 & 0.1266 & 0.1346 \\
$w\left(t_{3}\right)$ & 0.1335 & 0.1286 & 0.1613 & 0.1628 & 0.1242 & 0.1404 \\
$w^{*}(t)$ & 0.1504 & 0.1193 & 0.1688 & 0.1623 & 0.1210 & 0.1503 \\
\hline
\end{tabular}

TABle 5: The dynamic decision matrix $Y_{k}$.

\begin{tabular}{|c|c|c|c|}
\hline Target & $t_{1}$ & $t_{2}$ & $t_{3}$ \\
\hline$x_{1}$ & $\begin{array}{l}<[0.5901,0.6739] \\
{[0.0861,0.1607]>}\end{array}$ & $\begin{array}{l}<[0.6479,0.7300] \\
{[0.1438,0.2191]>}\end{array}$ & $\begin{array}{l}<[0.6812,0.7643] \\
{[0.0855,0.1623]>}\end{array}$ \\
\hline$x_{2}$ & $\begin{array}{l}<[0.5889,0.6750] \\
{[0.1294,0.2229]>}\end{array}$ & $\begin{array}{l}<[0.5778,0.6601] \\
{[0.1108,0.1798]>}\end{array}$ & $\begin{array}{l}<[0.5548,0.6366] \\
{[0.0981,0.1624]>}\end{array}$ \\
\hline$x_{3}$ & $\begin{array}{l}<[0.6512,0.7552] \\
{[0.0785,0.1526]>}\end{array}$ & $\begin{array}{l}<[0.7032,0.7970] \\
{[0.0829,0.1358]>}\end{array}$ & $\begin{array}{l}<[0.7793,0.8816] \\
{[0.0528,0.0955]>}\end{array}$ \\
\hline$x_{4}$ & $\begin{array}{l}<[0.4011,0.5069] \\
{[0.1826,0.2803]>}\end{array}$ & $\begin{array}{l}<[0.4363,0.5251] \\
{[0.1956,0.3145]>}\end{array}$ & $\begin{array}{l}<[0.4800,0.5596] \\
{[0.1559,0.2428]>}\end{array}$ \\
\hline$x_{5}$ & $\begin{array}{l}<[0.6265,0.7021] \\
{[0.1117,0.1973]>}\end{array}$ & $\begin{array}{l}<[0.6549,0.7393] \\
{[0.0746,0.1279]>}\end{array}$ & $\begin{array}{l}<[0.7120,0.7888] \\
{[0.1046,0.1527]>}\end{array}$ \\
\hline
\end{tabular}

threat assessment results, illustrating the effectiveness of the proposed method. Comparing the length of the uncertainty interval between the three methods in Table 9, we find that the uncertainty interval of the proposed method is less than that obtained by the method in $[4,44]$, which means that the proposed method in this paper reduces the uncertainty of 
TABLE 6: The sorting results at different time.

\begin{tabular}{lcccccc}
\hline Time & $x_{1}$ & $x_{2}$ & $x_{3}$ & $x_{4}$ & $x_{5}$ & Ranking result \\
\hline$t_{1}$ & 0.3853 & 0.4400 & 0.5220 & 0.1394 & 0.4831 & $x_{3}>x_{5}>x_{2}>x_{1}>x_{4}$ \\
$t_{2}$ & 0.5593 & 0.3832 & 0.6096 & 0.2164 & 0.4955 & $x_{3}>x_{1}>x_{5}>x_{2}>x_{4}$ \\
$t_{3}$ & 0.5694 & 0.3216 & 0.7350 & 0.2389 & 0.6295 & $x_{3}>x_{5}>x_{1}>x_{2}>x_{4}$ \\
Our method & 0.5554 & 0.3824 & 0.6821 & 0.2302 & 0.5875 & $x_{3}>x_{5}>x_{1}>x_{2}>x_{4}$ \\
\hline
\end{tabular}

TAвLE 7: The interval intuitionistic fuzzy values of each target by IVIFWG and IVIFWA.

\begin{tabular}{lcc}
\hline Target & IVIFWG & IVIFWA \\
\hline$\left(\left[\beta_{1 L}\left(x_{1}\right), \beta_{1 U}\left(x_{1}\right)\right],\left[\beta_{2 L}\left(x_{1}\right), \beta_{2 U}\left(x_{1}\right)\right]\right)$ & $([0.6217,0.6906],[0.1293,0.2214])$ & $([0.6453,0.7205],[0.1016,0.1950])$ \\
$\left(\left[\beta_{1 L}\left(x_{2}\right), \beta_{1 U}\left(x_{2}\right)\right],\left[\beta_{2 L}\left(x_{2}\right), \beta_{2 U}\left(x_{2}\right)\right]\right)$ & $([0.5368,0.6115],[0.1287,0.2119])$ & $([0.5591,0.6331],[0.1212,0.2007])$ \\
$\left(\left[\beta_{1 L}\left(x_{3}\right), \beta_{1 U}\left(x_{3}\right)\right],\left[\beta_{2 L}\left(x_{3}\right), \beta_{2 U}\left(x_{3}\right)\right]\right)$ & $([0.6889,0.7782],[0.0956,0.1673])$ & $([0.7523,0.8518],[0,0.1054])$ \\
$\left(\left[\beta_{1 L}\left(x_{4}\right), \beta_{1 U}\left(x_{4}\right)\right],\left[\beta_{2 L}\left(x_{4}\right), \beta_{2 U}\left(x_{4}\right)\right]\right)$ & $([0.4093,0.5007],[0.1931,0.2976])$ & $([0.4596,0.5405],[0.1475,0.2711])$ \\
$\left(\left[\beta_{1 L}\left(x_{5}\right), \beta_{1 U}\left(x_{5}\right)\right],\left[\beta_{2 L}\left(x_{5}\right), \beta_{2 U}\left(x_{5}\right)\right]\right)$ & $([0.6217,0.6936],[0.1359,0.2102])$ & $([0.7039,0.7762],[0,0.1299])$ \\
\hline
\end{tabular}

TABLE 8: The sorting results of different methods.

\begin{tabular}{lcccccc}
\hline Method & $x_{1}$ & $x_{2}$ & $x_{3}$ & $x_{4}$ & $x_{5}$ & Sorting result \\
\hline IVIFWG & 0.4876 & 0.3187 & 0.5986 & 0.1553 & 0.4884 & $x_{3}>x_{5}>x_{1}>x_{2}>x_{4}$ \\
IVIFWA & 0.5141 & 0.3531 & 0.6568 & 0.2094 & 0.5450 & $x_{3}>x_{5}>x_{1}>x_{2}>x_{4}$ \\
The proposed method & 0.5554 & 0.3824 & 0.6821 & 0.2302 & 0.5875 & $x_{3}>x_{5}>x_{1}>x_{2}>x_{4}$ \\
\hline
\end{tabular}

TABLE 9: Comparison of the lengths of different methods' uncertainty intervals.

\begin{tabular}{|c|c|c|c|c|c|c|}
\hline \multirow{2}{*}{$\begin{array}{l}\text { Target } \\
x_{1}\end{array}$} & \multicolumn{2}{|c|}{ IVIFWG } & \multicolumn{2}{|c|}{ IVIFWA } & \multicolumn{2}{|c|}{ The proposed method } \\
\hline & {$\left[\begin{array}{lll}0.0880 & 0.2491\end{array}\right]$} & 0.1611 & {$\left[\begin{array}{lll}0.0845 & 0.2530\end{array}\right]$} & 0.1685 & {$\left[\begin{array}{ll}0.0858 & 0.2447\end{array}\right]$} & 0.1590 \\
\hline$x_{2}$ & {$\left[\begin{array}{lll}0.1766 & 0.3344\end{array}\right]$} & 0.1579 & {$\left[\begin{array}{ll}0.1662 & 0.3197\end{array}\right]$} & 0.1543 & {$\left[\begin{array}{ll}0.1703 & 0.3245\end{array}\right]$} & 0.1542 \\
\hline$x_{3}$ & {$\left[\begin{array}{ll}0.0545 & 0.2155\end{array}\right]$} & 0.1610 & {$\left[\begin{array}{lll}0.0428 & 0.2477\end{array}\right]$} & 0.2047 & {$\left[\begin{array}{lll}0.0486 & 0.2007\end{array}\right]$} & 0.1521 \\
\hline$x_{4}$ & {$\left[\begin{array}{ll}0.2017 & 0.3977\end{array}\right]$} & 0.1959 & {$\left[\begin{array}{lll}0.1884 & 0.3929\end{array}\right]$} & 0.2046 & {$\left[\begin{array}{ll}0.1908 & 0.3756\end{array}\right]$} & 0.1849 \\
\hline$x_{5}$ & {$\left[\begin{array}{lll}0.0962 & 0.2424\end{array}\right]$} & 0.1462 & {$\left[\begin{array}{lll}0.0939 & 0.2961\end{array}\right]$} & 0.2022 & {$\left[\begin{array}{ll}0.0867 & 0.2223\end{array}\right]$} & 0.1356 \\
\hline
\end{tabular}

the target threat assessment results and improves the decision-making accuracy on target threat assessment results. Meanwhile, the method of [4] is a static assessment, and the proposed method also considers the time factor. Obviously, the method in this paper is more suitable for the threat assessment of a dynamic battlefield.

\section{Conclusion}

A dynamic air target threat assessment method based on interval intuitionistic fuzzy sets, game theory, and evidence reasoning methods is proposed. The main conclusions are as follows:

(1) The proposed method uses IVIFSs to construct an intuitionistic-valued fuzzy target information matrix, which can describe the ambiguity and uncertainty of battlefield target information more flexibly, making it more applicable in complex battlefield environments
(2) The optimal attribute weight is calculated by game theory, which overcomes the sensitivity to data of the interval intuitionistic fuzzy entropy, making the assessment result more reliable

(3) The simulation results show that the proposed method can reduce the uncertainty of the target threat assessment results and meet the dynamically variable battlefield requirements

The proposed method can also be applied in pattern recognition, project selection, and many other areas of decision-making problems.

In the future, we will focus on hybrid multiattribute target threat assessment to address heterogeneous information in different battlefield environments.

\section{Data Availability}

The data used to support the findings of this study are included within the article. 


\section{Conflicts of Interest}

The authors declare that they have no conflicts of interest.

\section{Acknowledgments}

This work was supported by the National Natural Science Foundation of China (grant no. 61972363).

\section{References}

[1] Y. Gao, D.-S. Li, and H. Zhong, "A novel target threat assessment method based on three-way decisions under intuitionistic fuzzy multi-attribute decision making environment," Engineering Applications of Artificial Intelligence, vol. 87, Article ID 103276, 2020.

[2] J.-F. Feng, Q. Zhang, J.-H. Hu, and A. Liu, "Dynamic assessment method of air target threat based on improved GIFSS," Journal of Systems Engineering and Electronics, vol. 30, no. 3, pp. 525-534, 2019.

[3] L.-F. Yue, R.-N. Yang, J.-L. Zuo, H. Luo, and Q.-L. Li, “Air target threat assessment based on improved moth flame optimization-gray neural network model," Mathematical Problems in Engineering, vol. 2019, Article ID 4203538, 14 pages, 2019.

[4] D. Kong, T. Chang, Q. Wang, H. Sun, and W. Dai, “A threat assessment method of group targets based on interval-valued intuitionistic fuzzy multi-attribute group decision-making," Applied Soft Computing, vol. 67, pp. 350-369, 2018.

[5] S. Kumar and B. K. Tripathi, "Modelling of threat evaluation for dynamic targets using Bayesian network approach," Procedia Technology, vol. 24, pp. 1268-1275, 2016.

[6] Y. Wang, Y. Sun, J.-Y. Li, and S.-T. Xia, "Air defense threat assessment based on dynamic Bayesian network," in Proceedings of the 2012 International Conference on Systems and Informatics (ICSAI2012), pp. 721-724(in Chinese), Yantai, China, May 2012.

[7] Y. F. Liu, S.-D. Chen, Z.-Y. Zhao, and A. Zhang, "Threat assessment of manned/unmanned combat aerial vehicle formation air-to-ground attack based on FBNs," Systems Engineering and Electronics, vol. 34, no. 8, pp. 1636-1639, 2012.

[8] H. Lee, B. J. Choi, C. O. Kim, J. S. Kim, and J. E. Kim, “Threat evaluation of enemy air fighters via neural network-based Markov chain modeling," Knowledge-Based Systems, vol. 116, pp. 49-57, 2017.

[9] H. Yang, C. Han, C. Han, and C. Tu, "Air targets threat assessment based on BP-BN," Journal of Communications, vol. 13, no. 1, pp. 21-26, 2018.

[10] L.-L. Xie and L. Han, "Threat ordering of the air-raid targets threat based on the rough set theory," Fire Control \& Command Control, vol. 34, no. 9, pp. 61-64, 2009, (in Chinese).

[11] S. Ma, H. Zhang, and G. Yang, "Target threat level assessment based on cloud model under fuzzy and uncertain conditions in air combat simulation," Aerospace Science and Technology, vol. 67, pp. 49-53, 2017.

[12] G.-G. Wang, L.-H. Guo, and H. Duan, "Wavelet neural network using multiple wavelet functions in target threat assessment," The Scientific World Journal, vol. 2013, pp. 1-7, Article ID 632437, 2013.

[13] H.-B. Liu, H.-P. Wang, and L.-D. Shen, "Target threat assessment using SAPSO and grey neural network," Journal of Northwestern Polytechnical University, vol. 34, no. 1, pp. 2532, 2016, (in Chinese).
[14] L. A. Zadeh, "Fuzzy sets," Information and Control, vol. 8, no. 3, pp. 338-353, 1965.

[15] J. Huang, B. C. Li, and Y. J. Zhao, "Target threat assessment based on intuitionistic fuzzy sets choquet integral," Applied Mechanics and Materials, vol. 433-435, pp. 736-743, 2013.

[16] E. Azimirad and J. Haddadnia, "Target threat assessment using fuzzy sets theory," International Journal of Advances in Intelligent Informatics, vol. 1, no. 2, pp. 57-74, 2015.

[17] Y. Xu, Y. Wang, and X. Miu, "Multi-attribute decision making method for air target threat evaluation based on intuitionistic fuzzy sets," Journal of Systems Engineering and Electronics, vol. 23, no. 6, pp. 891-897, 2012.

[18] K. Zhang, W.-R. Kong, W. Kong, P. Liu, Y. Lei, and J. Zou, "Assessment and sequencing of air target threat based on intuitionistic fuzzy entropy and dynamic VIKOR," Journal of Systems Engineering and Electronics, vol. 29, no. 2, pp. 305-310, 2018.

[19] K. Atanassov and G. Gargov, "Interval valued intuitionistic fuzzy sets," Fuzzy Sets and Systems, vol. 31, no. 3, pp. 343-349, 1989.

[20] R. Verma and B. D. Sharma, "Exponential entropy on intuitionistic fuzzy sets," Kybernetika, vol. 49, no. 1, pp. 111-127, 2013.

[21] R. Verma and B. Sharma, "R-norm entropy on intuitionistic fuzzy sets," Journal of Intelligent \& Fuzzy Systems, vol. 28, no. 1, pp. 327-335, 2015.

[22] R. Verma and B. D. Sharma, "On generalized intuitionistic fuzzy divergence (relative information) and their properties," Journal of Uncertain Systems, vol. 6, no. 4, pp. 308-320, 2012.

[23] R. Verma and B. D. Sharma, "Intuitionistic fuzzy jensen-rényi divergence: applications to multiple attribute decision making," Informatica, vol. 37, no. 4, pp. 399-409, 2013.

[24] K. Guo and H. Xu, "Knowledge measure for intuitionistic fuzzy sets with attitude towards non-specificity," International Journal of Machine Learning and Cybernetics, vol. 10, no. 7, pp. 1657-1669, 2019.

[25] H. Zhang, J. Xie, W. Lu, Z. Zhang, and X. Fu, "Novel ranking method for intuitionistic fuzzy values based on information fusion," Computers \& Industrial Engineering, vol. 133, pp. 139-152, 2019.

[26] R. Verma and J. M. Merigó, “A new decision making method using interval-valued intuitionistic fuzzy cosine similarity measure based on the weighted reduced intuitionistic fuzzy sets," Informatica, vol. 31, no. 2, pp. 399-433, 2020.

[27] B. Oztaysi, S. Cevik Onar, C. Kahraman, and M. Yavuz, "Multi-criteria alternative-fuel technology selection using interval-valued intuitionistic fuzzy sets," Transportation Research Part D: Transport and Environment, vol. 53, pp. 128148, 2017.

[28] D. Yu, "Hydrogen production technologies evaluation based on interval-valued intuitionistic fuzzy multiattribute decision making method," Journal of Applied Mathematics, vol. 2014, pp. 1-10, Article ID 751249, 2014.

[29] A. De, S. Das, and S. Kar, "Multiple attribute decision making based on probabilistic interval-valued intuitionistic hesitant fuzzy set and extended TOPSIS method," Journal of Intelligent \& Fuzzy Systems, vol. 37, no. 4, pp. 5229-5248, 2019.

[30] A. De, P. Kundu, S. Das et al., "A ranking method based on interval type-2 fuzzy sets for multiple attribute group decision making," Soft Computing, vol. 24, no. 1, pp. 131-154, 2020.

[31] M.-W Zhao, G.-W. Wei, C. Wei et al., "Improved TODIM method for intuitionistic fuzzy MAGDM based on cumulative prospect theory and its application on stock investment selection," International Journal of Machine Learning and Cybernetics, vol. 12, no. 3, pp. 891-901, 2021. 
[32] S.-H. Cheng, "Autocratic multiattribute group decision making for hotel location selection based on interval-valued intuitionistic fuzzy sets," Information Sciences, vol. 427, pp. 77-87, 2018.

[33] G. Wei, "Some induced geometric aggregation operators with intuitionistic fuzzy information and their application to group decision making," Applied Soft Computing, vol. 10, no. 2, pp. 423-431, 2010.

[34] A. Makui, M. R. Ghlamian, and S. E. Mohammadi, "Supplier selection with multi-criteria group decision making based in interval-valued intuitionistic fuzzy sets (case study on a project-based company)," Journal of Industrial and Systems Engineering, vol. 8, no. 4, pp. 19-38, 2015.

[35] J.-q. Wang, R.-r. Nie, H.-y. Zhang, and X.-h. Chen, "Intuitionistic fuzzy multi-criteria decision-making method based on evidential reasoning," Applied Soft Computing, vol. 13, no. 4, pp. 1823-1831, 2013.

[36] Q. Gao and D.-L. Xu, "An empirical study on the application of the Evidential Reasoning rule to decision making in financial investment," Knowledge-Based Systems, vol. 164, no. 15, pp. 226-234, 2019.

[37] D.-L. Xu, J.-B. Yang, and Y.-M. Wang, "The evidential reasoning approach for multi-attribute decision analysis under interval uncertainty," European Journal of Operational Research, vol. 174, no. 3, pp. 1914-1943, 2006.

[38] S.-M. Chen and C.-H. Chiou, "Multiattribute decision making based on interval-valued intuitionistic fuzzy sets, PSO techniques, and evidential reasoning methodology," IEEE Transactions on Fuzzy Systems, vol. 23, no. 6, pp. 1905-1916, 2015.

[39] S. E. Mohammadi and A. Makui, "Multi-attribute group decision making approach based on interval-valued intuitionistic fuzzy sets and evidential reasoning methodology," Soft Computing, vol. 21, no. 17, pp. 5061-5080, 2017.

[40] S.-M. Chen, S.-H. Cheng, and C.-H. Chiou, "Fuzzy multiattribute group decision making based on intuitionistic fuzzy sets and evidential reasoning methodology," Information Fusion, vol. 27, pp. 215-227, 2016.

[41] T.-T. Bao, X.-L. Xie, P.-Y. Long, and Z.-K. Wei, "MADM method based on prospect theory and evidential reasoning approach with unknown attribute weights under intuitionistic fuzzy environment," Expert Systems with Applications, vol. 88, pp. 305-317, 2017.

[42] J. Yuan and X. Luo, "Approach for Multi-attribute decision making based on novel intuitionistic fuzzy entropy and evidential reasoning," Computers \& Industrial Engineering, vol. 135, pp. 643-654, 2019.

[43] J. Ye, "Multicriteria fuzzy decision-making method based on a novel accuracy function under interval-valued intuitionistic fuzzy environment," Expert Systems with Applications, vol. 36, no. 3, pp. 6899-6902, 2009.

[44] C. P. Wei, P. Wang, and Y. Z. Zhang, "Entropy, similarity measure of interval-valued intuitionistic fuzzy sets and their applications," Information Sciences, vol. 181, no. 19, pp. 4273-4286, 2011.

[45] S. Das, B. Dutta, and D. Guha, "Weight computation of criteria in a decision-making problem by knowledge measure with intuitionistic fuzzy set and interval-valued intuitionistic fuzzy set," Soft Computing, vol. 20, no. 9, pp. 3421-3442, 2016. 